\title{
A case study on Hoeamsa Temple, Korea: technical examination and identification of pigments and paper unearthed from the temple site
}

\author{
InHee Go ${ }^{1}$, SeongWoo Mun², JangJon Lee ${ }^{3}$ and HyeYoung Jeong ${ }^{4^{*}}$
}

\begin{abstract}
This study applied various scientific analyses to one fragment of paper and three pigments excavated from earthenware found in the Hoeamsa Temple site at Yangju, Korea, which is believed to have been built in the early twelfth century. Radiocarbon dating of the paper fragment suggests a manufacture date between 1460 and 1646 (at a 95\% confidence interval). It was estimated to have been used during the early and middle period of the Joseon dynasty (1391-1776), when the Hoeamsa Temple site was rebuilt. In addition, by staining the fiber of the paper fragment with Graff " $C$ " stain, the paper's raw material was identified as paper mulberry through dislocation, cross-marking, and transparent membrane, which are characteristics of the bast fiber. Efforts were made to identify their material properties and manufacturing techniques of the three types of pigments. Color difference analysis was performed by distributing the pigments in large areas to reveal characteristic differences according to the color difference of the pigment. We found that green-type pigments are malachite and atacamite, red-type pigments are hematite based on the element Fe, and white-type pigments are quartz and muscovite based on the elements Si and Al. In addition, as the size distribution of the three types of pigments is wide and has a multi-peak distribution curve, it was concluded that the pigments were used without purification.
\end{abstract}

Keywords: Ancient pigment, Hoeamsa Temple, Paper, Bast fiber, Dancheong, Joseon dynasty

\section{Introduction}

The Hoeamsa Temple site in Yangju, Gyeonggi province, South Korea, was designated as Historic Site No. 128 in 1964 (Fig. 1a). Though its establishment date is unclear, the first documentary record of Hoeamsa Temple is found in the book Dongguk Yeoji Seungram (1481) that dates it back to 1174. The book reveals that envoys from China's Jin (金) dynasty visited the temple. The monument to Taegosa Wonjeungguksa in Goyang was erected to commemorate Venerable Wonjeung (1301-1382), an

\footnotetext{
*Correspondence: elisul@korea.kr

${ }^{4}$ Cultural Heritage Conservation Science Center, National Research Institute of Cultural Heritage, Daejeon 34122, Republic of Korea.

Full list of author information is available at the end of the article
}

eminent monk in the late Goryeo dynasty. According to the record, "I left home at the age of 13 and became a disciple of Gwangii (廣智) at Hoeamsa". Hoeamsa is confirmed here to have already been built in 1313. Despite being located in a mountainous region, a south corridor was built that could be seen from temples in the plains and that exhibited the palace and temple arrangement styles of the Goryeo dynasty [1-3]. Therefore, it is estimated to have been constructed in the late twelfth century.

According to Lee [4], analytical research of pigments in Korea began after John Winter's study on the component analysis of ancient Korean pigments [5]. Throughout the 1990s and 2000s [6], researchers analytically investigated the pigments applied to murals, portraits, and decorative
Springer Open

(c) The Author(s) 2022, corrected publication 2022. Open Access This article is licensed under a Creative Commons Attribution 4.0 International License, which permits use, sharing, adaptation, distribution and reproduction in any medium or format, as long as you give appropriate credit to the original author(s) and the source, provide a link to the Creative Commons licence, and indicate if changes were made. The images or other third party material in this article are included in the article's Creative Commons licence, unless indicated otherwise in a credit line to the material. If material is not included in the article's Creative Commons licence and your intended use is not permitted by statutory regulation or exceeds the permitted use, you will need to obtain permission directly from the copyright holder. To view a copy of this licence, visit http://creativecommons.org/licenses/by/4.0/. The Creative Commons Public Domain Dedication waiver (http://creativecommons.org/publicdomain/zero/1.0/) applies to the data made available in this article, unless otherwise stated in a credit line to the data. 


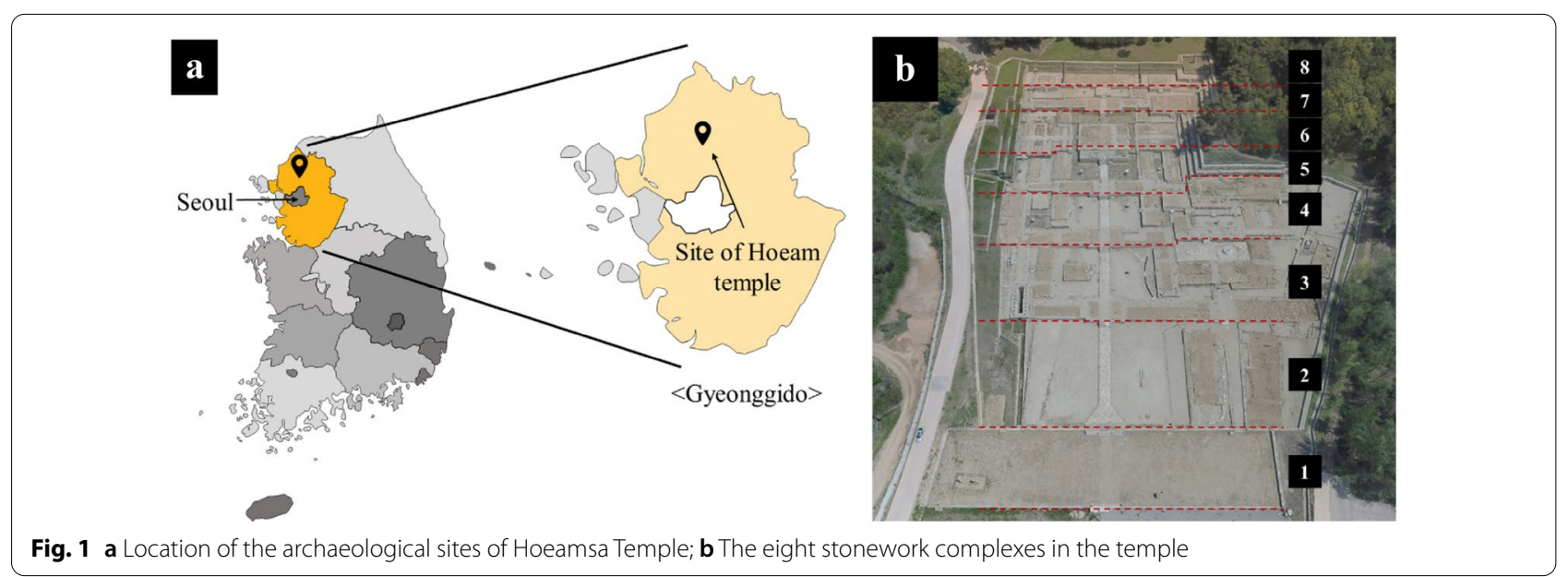

paintings, and studies on the reproduction and restoration of traditional pigments found whiting, noerok, hematite, copper pigments, and ink to be the main ingredients $[7,8]$. Innovation in this field continues and recent efforts have been made to address limitations of existing analytical techniques or to apply new ones. Every year new analytical studies emerge on the various cultural property pigments, including murals, Buddhist paintings, portraits, decorative paintings, and dancheong $[4,9]$.

Recently, other methods of analysis are also being widely used [10]. Several studies have been published on identifying raw materials of pigments using Raman spectroscopy and Raman matching [11], on identifying pigments using a non-destructive technique [12], on pigment particle size using Raman half-width [13], and on identification and diagnosis of pigments using Terahertz radiation [14].

Most of the cases used in the analysis of dancheong pigments in Korea are those of pigments remaining in wooden structures $[15,16]$. The National Research Institute of Cultural Heritage in South Korea investigated and analyzed the dancheong pigments of 44 wooden structures spread throughout Korea for four years [17, 18]. Most of them were created until the late Goryeo-Joseon period. However, this scientific data is also an analysis of pigments remaining in wooden structures. Pigments excavated from the Hoeamsa Temple site have been packaged and stored in handmade paper, and this is the only case in Korea where a lump of pigments has been officially stored and discovered.

In Korea, due to the rapid progress of industrialization since the 1970s, dancheong pigments have been replaced by chemical pigments, which are cheap and have good color fastness. In 2014, regarding dancheong construction in the standard specification for cultural property repair [19], it is stipulated that certain materials are used for the dancheong pigments and color numbers were designated in the specification, whilst chemical pigments are reported as a type of dancheong pigment. In addition, dancheong pigments are used based on the contents of the standard specification, unless otherwise specified in the design or instructed by the responsible authority. Consequently, the use of traditional dancheong pigments is in decline, and the remaining ancient dancheong architecture is being replaced with chemical pigments.

In addition, there are insufficient data and records on both the use of mineral pigments obtained from nature, and the current state of the remaining ancient dancheong buildings, which are declining in number due to their being replaced with chemical pigments. Consequently, it is difficult to secure scientific data concerning ancient dancheong. As the Hoeamsa Temple site was built in the early twelfth century and was well supported by kings until the end of the Joseon dynasty, this study is significant as it analyzes the raw materials of pigments used during the early and mid-Joseon dynasty (1391-1776). Furthermore, our findings may be used as basic data to elucidate the characteristics of pigments used in those eras.

\section{Research aim}

The main aim of this study was to examine the ancient paper and pigments found in historic sites. We aimed to identify the pigments used in early and mid-Joseon dynasties (1392-1776) and obtain new information about traditional dancheong pigments. The raw materials of the paper fragment were identified through the morphological characteristics of the fibers, and the dates were estimated by radiocarbon dating. The characteristics of the pigments were confirmed through analysis of component, particle size, color, and crystal structure. Through these processes, both the characteristics of the raw 
materials of paper and pigments used in temples in the early and mid-Joseon dynasty and the production process of pigments were identified, which are anticipated to serve as basic scientific data for preserving and restoring temples and dancheong.

\section{Materials and analysis methods Materials}

The samples used in this study were pigments excavated from the Hoeamsa Temple site in Yangju (Fig. 1b): the pigments were wrapped in paper and placed in pottery. There were 16 pigments and one paper fragment. Based on color, three samples were selected from the 16 pigments, which were relatively unmixed. Figure 2 demonstrates the excavated pottery (Fig. 2a), pigments (Fig. 2b-d), and paper (Fig. 2e).

\section{Analysis methods Paper analysis}

The excavated pigments and paper specimens were radiocarbon dated using the accelerator mass spectrometer (AMS) 1MV HVE 4110 (HVEE, The Netherlands). For sample pretreatment, the paper specimen was washed with deionized water to remove soil on the surface and chemically treated using the AAA method (acid-alkaliacid, $0.5 \mathrm{M} \mathrm{HCl}, 0.1 \mathrm{NaOH}, 0.5 \mathrm{M} \mathrm{HCl}$ [ [20, 21]. The program Oxcal v4.2.4 was used to convert the radiocarbon dating into calendar dating, and the Intcal 20 calibration curve was applied [22].

The paper fiber identification was based on the Graff " $C$ " method, which is accessible in ISO 9184-4, and the fiber morphology was observed using a Nikon fluorescent microscope (Eclipse Ni, Japan) [23]. A low vacuum electron microscope (Hitachi TM3000, Japan) was used to observe the sample surface.

\section{Pigment analysis}

The stereomicroscope BX51 from Olympus was used to confirm whether the pigments excavated from the Hoeamsa Temple site were mixed. To measure the color difference of the pigments, a color difference meter (spectro-guide) from Gardner was used to express the CIE $L^{*}$, $\mathrm{a}^{*}$, and $\mathrm{b}^{*}$ values. X-ray diffraction spectroscopy (Mepyrean, Panalyical, The Netherlands) was used to analyze the main component minerals of the pigments. The analysis conditions were $40 \mathrm{kV}, 40 \mathrm{~mA}, 2$ theta, range of $5^{\circ}-80^{\circ}$, scanning interval of $0.04^{\circ}$, and scanning time of $0.5 \mathrm{~s}$. Measurements were performed through the continuous scan method. To analyze the microstructure of the excavated pigments, scanning electron microscopyenergy dispersive spectroscopy (SEM-EDS) was applied through SEM of Jeol (JSM-5910LV, Japan), and the surface of the pigments was coated in platinum $(\mathrm{Pt})$. The principal element analysis was conducted using an $\mathrm{x}$-ray fluorescence spectrometer (Zetium, Panalyical, The Netherlands). The white and red pigments were analyzed using a standard calibration curve, while the green pigments were analyzed using the software Omnian, which is a semi-quantitative program using standard samples provided by Panalytical. To measure the particle-size distribution, $0.2 \mathrm{~g}$ of the pigment was dispersed for $24 \mathrm{~h}$ using $20 \mathrm{ml}$ of $1 \%$ sodium hexametaphosphate (SigmaAldrich), and Masterisizer 2000 (Malvern, UK) was used.

\section{Results and discussion \\ Paper analysis Radiocarbon dating}

As in Fig. 3, the radiocarbon dating of the paper sample was found to be $340 \pm 34$ (BP). Years BP [before present, (BP)] were calculated in the 1950s using Libby half-life ( $5568 \pm 30$ years): the year 1950 was set as 0 , as there was a drastic change in the ratio of radiocarbon components in the atmosphere; thus, dating is difficult to measure after this time $[24,25]$.

As shown in Fig. 3 and Table 1, through radiocarbon dating, the paper sample was determined to be from CE 1455-1646 with a 95\% confidence interval and an error range of 191 years. According to Kim Hong-sik [26], "Hoeamsa has been a subject of interest to many people as a grand Buddhist temple of the last Goryeo dynasty and early Joseon dynasty period. Hoeamsa's

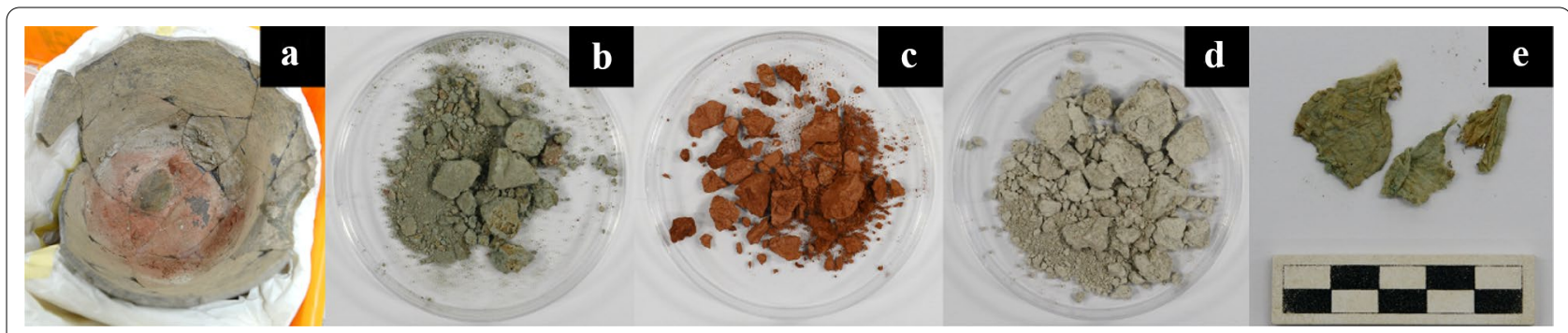

Fig. 2 Pictures of artifacts (a pottery containing pigments and paper; $\mathbf{b}$ green pigment; c red pigment; $\mathbf{d}$ white pigment; e paper) 


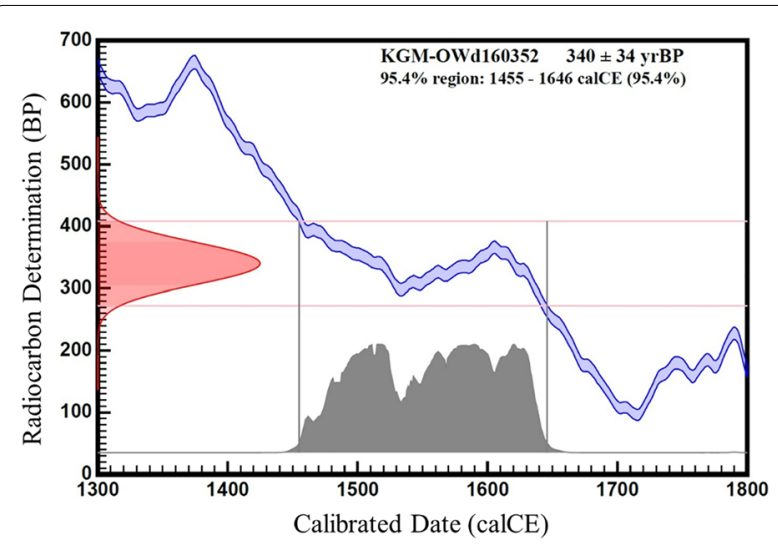

Fig. 3 Probability profiles of radiocarbon date (Y-axis) and calibrated date (X-axis) for the paper fragment

Table 1 Result of radiocarbon dating (CE: common era)

\begin{tabular}{ll}
\hline Radiocarbon date & Calibrated data ${ }^{14} \mathrm{C}$ date range \\
\hline$(\mathrm{yrBP} \pm 1 \sigma)$ & Data range $(95.4 \%)$ \\
$340 \pm 34$ & $1455(95.4 \%) 1646$ CalCE \\
\hline
\end{tabular}

reconstruction took place after 1472 .... Furthermore, "the appearance of the architecture is very similar to the late Goryeo dynasty and early Joseon dynasty".

The paper is therefore thought to have originated sometime between the early and mid-Joseon dynasty and is considered to have been manufactured after the establishment of Hoeamsa. Paper from the Joseon dynasty was generally made of pure mulberry trees, and Gangwon Province, in particular, was so prolific in producing handmade paper that there were 15 paper manufacturing plants making handmade paper during the Joseon dynasty [27]. Given that Gangwon Province consists of mountainous terrain located in the middle eastern part of the Korean Peninsula [28], making it difficult to access from the outside, and that the Hoeamsa Temple was where King Taejo stayed, due to which it has maintained a close relationship with the royal family [29], it is believed that handmade paper excavated from the temple site was procured and supplied locally.

\section{Morphological characteristics}

Paper fibers can largely be classified into wood and nonwood fibers, and the latter can be further subdivided into herbaceous, bast, seedling, and leaf fibers. The inner bark of some dicotyledonous plants, including flax, hemp, kenaf, paper-mulberry, gampi, and mitsumata, is used to obtain bast fiber. Mulberry (Bruroussonetia papyrifera, Vent.), bamboo (Phyllostachys edulis, Carr.), mitsumata
(Edgeworthia papyrifera), and Gampi (Wikstroemia canescens, Meisn.) are the most important paper fibers in the East [30]. Bamboo can be distinguished from mulberry, mitsumata, and gampi by identifying the presence of long, fairly narrow fibers, and small, rectangular, and thick-walled parenchyma cell elements. In particular, Korea uses mulberry (Bruroussonetia papyrifera, Vent.) as its main raw material [31]. Mitsumata and gampi have a broad central portion of fibers and are distinct from common bast fibers. Mulberry fiber features a thick fiber wall, with distortion and joints also observed. An important feature of oak mulberry fibers that distinguishes them from other bast fibers is the presence of thin transparent membranes [32, 33].

Korea has a record of producing handmade Korean paper from the Goryeo dynasty. Korean paper was selected as a major export item in recognition of its superb quality until the late Joseon dynasty. The reason is that, unlike Xuan paper in China and Washi in Japan, there is a large difference in the degree of orientation of the paper $[34,35]$. On using a stereoscopic microscope on the surface fiber shape, it was observed that thin and long fibers were entangled and that the sample was too small to distinguish the direction of the fibers, even after attempting to distinguish the degree of orientation $[39,40]$. An excavated paper fragment with pigments is shown in the photographs below (Fig. 4).

The fibers of the paper wrapping the pigments reacted by turning reddish brown in the Graff " $\mathrm{C}$ " stain [37]. As shown in Fig. $5 \mathrm{c}$, the transparent membrane enveloped around the fiber and the cross-marking, dislocation, and longitudinal striations of the fiber were observed, thereby confirming that the specimen is paper-mulberry bast fiber [32, 38-40].

The surface of a paper fragment was magnified and examined by scanning it with an electron microscope. As with the optical microscope, this allowed us to observe the anatomical characteristics of the bast fibers (Fig. 6). Impurities were present on the fiber surface; however, since no irregular particles were observed, there seems to be no separate inorganic filler (calcium carbonate is sometimes applied to make the surface of the paper smooth) [36].

\section{Pigment analysis Microscopy observation}

Close-up images were captured via stereomicroscope to more precisely observe the pigments excavated from the Hoeamsa Temple site, and green, red, and white pigments were detected (Fig. 7). Green pigment was mixed with the red pigment (Fig. 7a), while white pigment 

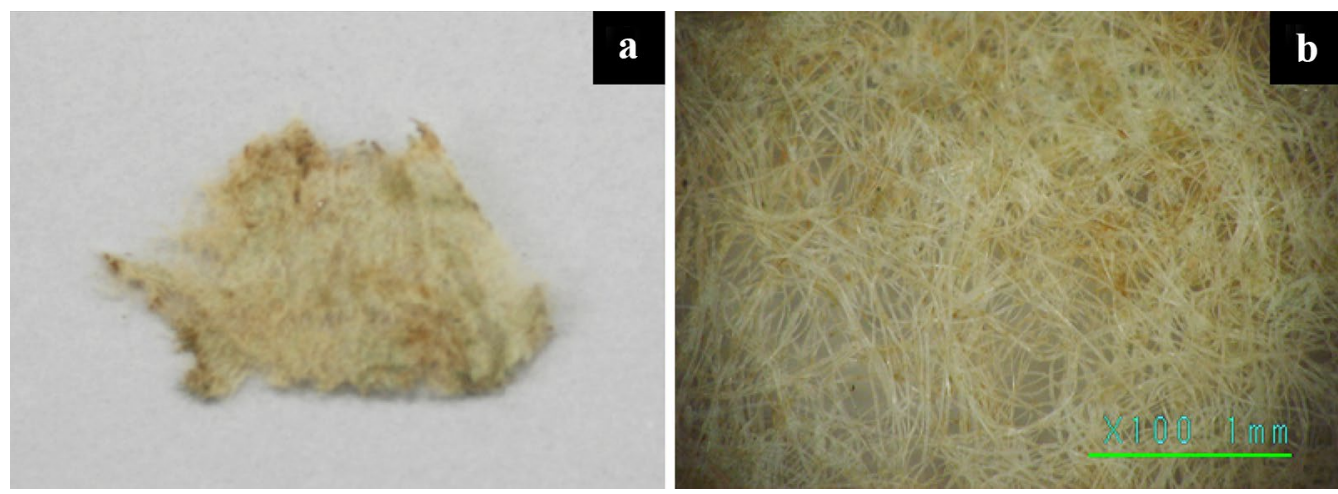

Fig. 4 Photographs of the paper fragment (a paper fragment; $\mathbf{b}$ microscope image 100x)
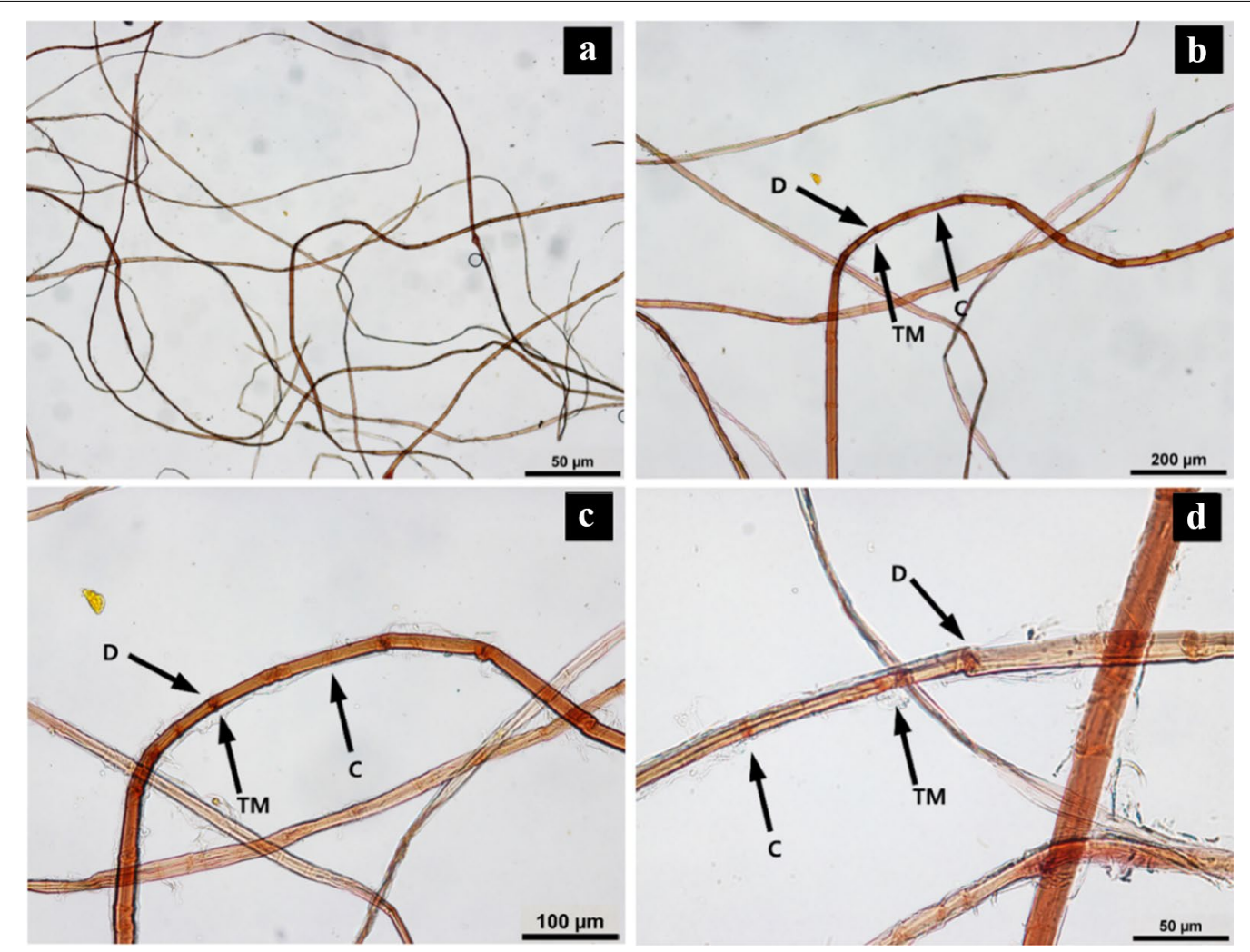

Fig. 5 Microscope image of the fiber color reaction (a 40x, b 100x, c 200x, d 400x; Arrow C: cross-marking; Arrow D: dislocation; Arrow TM: transparent membrane)

was partially mixed with red pigment (Fig. 7b), and red pigment was partially mixed with the white pigment (Fig. 7c).

\section{Color difference analysis}

The hiding and tinting power of a pigment is dependent on particle size. Modern pigments are manufactured with uniform particle size to maintain uniform hiding power and coloring power. However, unlike modern pigments, historical pigments affect the color of the paint layer because they are not all composed of particles of uniform size [41]. The colors of pigments are thus quantified through the chromaticity measurements to identify the objective color value of pigments and distinguish them from the color characteristics of similar systems [42, 43]. 

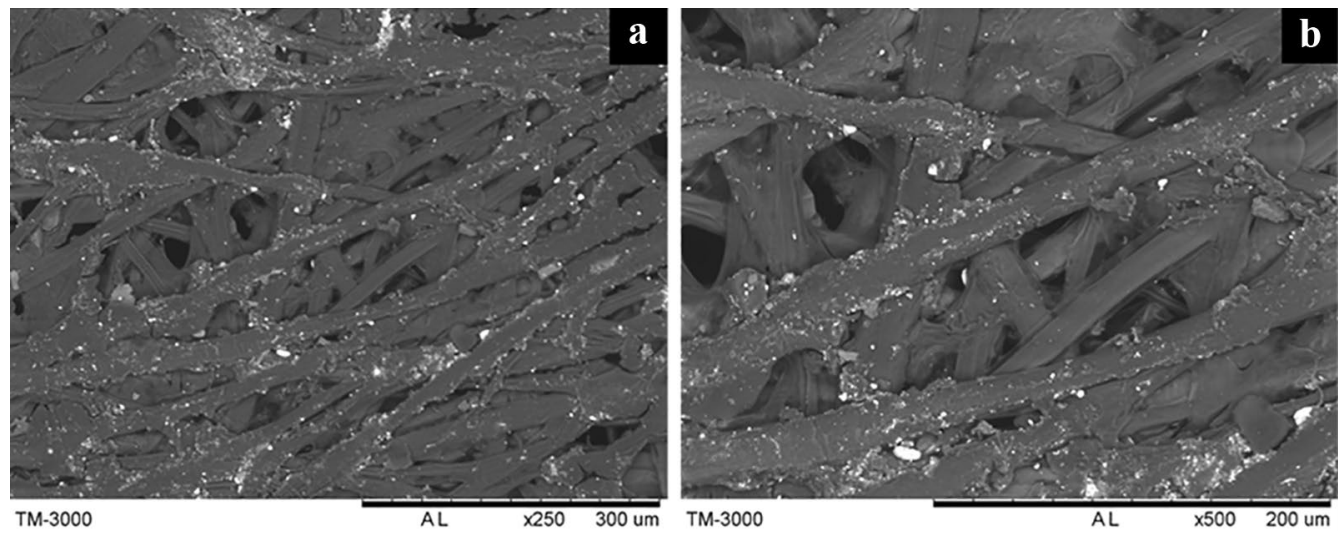

Fig. 6 Surface image of the paper fragment (a 250x; b 500x)
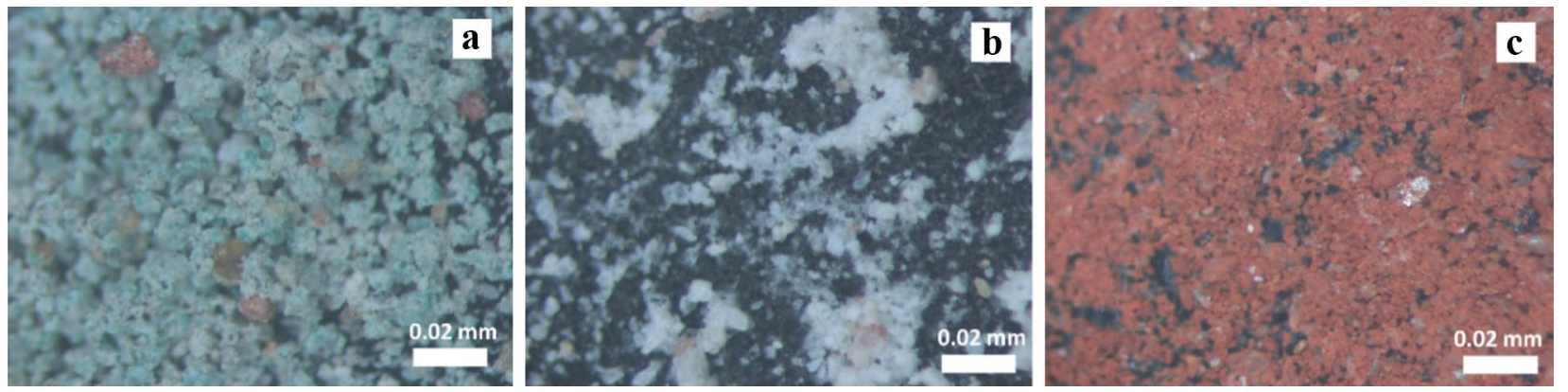

Fig. 7 Image of optical microscopy (a green pigment; $\mathbf{b}$ white pigment; $\mathbf{c}$ red pigment)

The $L^{*}$ value, which measures brightness, ranges from 41.59 to 79.05 . The white pigment showed the highest brightness value at 79.05 , while the green pigment and red pigment had values of 58.20 and 41.59 , respectively. In terms of brightness value, the three types of pigments reveal a distinct difference within a wide range. The $\mathrm{a}^{*}$ value, which indicates the measure of green $\left(-\mathrm{a}^{*}\right)$ and red $\left(+\mathrm{a}^{*}\right)$, ranged from -2.25 to 22.75 . Of particular interest is the $\mathrm{a}^{*}$ value of the red pigment that revealed a high degree of redness at 22.75 , while the $a^{*}$ value of the green pigment was the lowest at -2.25 . The $b^{*}$ value, which indicates the measure of blue $\left(-b^{*}\right)$ and yellow $\left(+b^{*}\right)$, ranged from 7.44 to 26.26 . The $b^{*}$ value of the red pigment was the highest at 26.26 , while that of the white pigment was the lowest at 7.44 (Fig. 8).

\section{Component mineral analysis}

An X-ray diffraction analysis was performed to identify the mineral species of the green, white, and red pigments (Fig. 9). Quartz was detected in all of the pigments. The green pigment showed peaks of malachite, atacamite, cerussite, and quartz, and a small amount of illite. The components that can reveal the green color would be

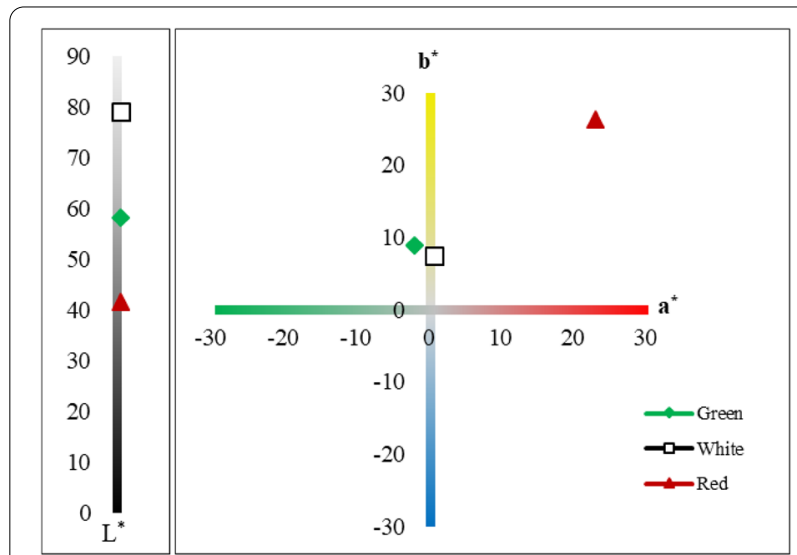

Fig. 8 Chromaticity diagram of pigments

malachite and atacamite, which have the element $\mathrm{Cu}$ as the main component, and quartz and illite can be discerned with the components contained in the soil. Cerussite $\left(\mathrm{PbCO}_{3}\right)$ is a white raw material and implies the possibility that the workers at the time might have mixed the color white to elicit the color they wanted. Reports of 


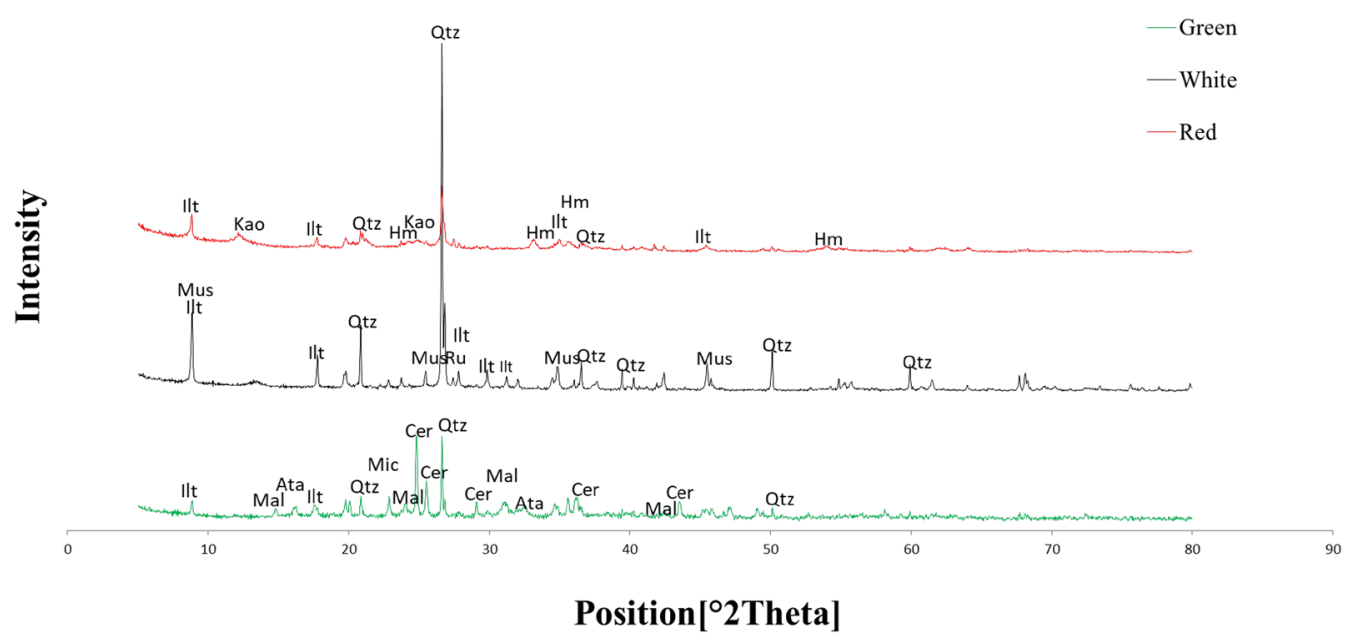

Fig. 9 X-ray diffraction patterns for each pigment (Cer, Cerussite; Qtz, Quartz; Mal, Malachite; Ata, Atacamite; Mus, Muscovite; Ilt, Illite; Hm, Hematite; Kao, Kaolinite)

the use of white lead in murals and paintings support this possibility [44]. White pigments are mostly made of clay minerals having quartz, muscovite, and illite as the main constituent minerals and the red pigment showed quartz, hematite, illite, and kaolinite. Minerals are identified, and it is judged that the red color is due to iron oxide derived from hematite.

\section{SEM-EDS analysis}

Based on the SEM-EDS mapping analysis (Table 2), $\mathrm{Cu}$ comprised $4.09 \%$ of the green pigment. Further, C, O, $\mathrm{Si}, \mathrm{Pb}$, and $\mathrm{Cl}$ were also detected. This SEM-EDS result, which contains elements $\mathrm{Cu}$ and $\mathrm{Cl}$, supports the results of the X-Ray Diffraction. Previous studies have reported that atacamite particles are angled and very thick, and that lighter green particles have higher $\mathrm{Cu}$ and $\mathrm{Cl}$ content [45]. A small amount of atacamite is present with $\mathrm{Cl}$ content of $0.33 \%$. All in all, regarding the pigments used in green-based dancheong detected in Korean cultural properties, atacamite accounts for $45 \%$, celadonite $39 \%$, the pigments used in combination with other pigments (such as atacamite + cerusite or atacamite + carbon black) $15 \%$, and malachite $1 \%$ [46]. In addition, recently reported research results show that copper chloride was widely used among green pigments used in large Buddhist banner paintings during the Joseon dynasty, and the possibility of copper trihydroxychloride (atacamite, paratakamite, botalachite, etc.,) naturally or artificially manufactured as natural minerals continues to be raised [47-49]. In particular, the main elements constituting the copper chloride pigment were $\mathrm{Cu}, \mathrm{Sn}, \mathrm{Zn}$, and $\mathrm{Pb}$ [50]. As can be seen from the results of the green pigment SEM-EDS in this study, the elements $\mathrm{Cu}, \mathrm{Pb}$, and
Sn were detected, all possibilities that the element $\mathrm{Pb}$ was derived either from copper chloride or from Sn and cerussite need to be taken into consideration.

The principal element of the white pigment is $\mathrm{Si}$ (18.46\%); $\mathrm{O}, \mathrm{C}, \mathrm{Al}$, and $\mathrm{K}$ were also detected. The red pigment showed $7.81 \%$ of $\mathrm{Fe}$, and consists of $\mathrm{O}, \mathrm{C}, \mathrm{Si}$, and $\mathrm{Al}$.

The microstructure results through SEM analysis are as below (Table 3). It is reported that both malachite and chlorite are generally fibrous and have a variolitic and botryoidal structure with a spherical appearance when aggregation occurs [51]. As confirmed through SEM, fine spherical particles of the green pigment aggregated to form a single mass as a botryoidal structure. In previous studies, hematite was reported to be flat-like, and large with small aggregates layered together [52]. However, hexagonal or anhedral particles were not detected in the white pigment; the pigment showed a flat surface, thus differing from the form of the red pigment, and the white pigment had an amorphous shape. Only the surface of the particles is formed in a plate-shape, which was observed to be smooth. Hematite is known to appear as aggregates of fibrous crystals, or as mica hematite in a flat shape in sheets. In the red pigment, the flat-like crystals, with smooth surfaces, were densely stacked and formed a single aggregate. Groups of fibrous crystals were also observed. It has been reported that quartz is so hard due to anhedral crystal growth and that in rare cases some crystals may exist in subhedral fragments of hexagonal prismatic form [51].

Table 3 shows the result of the SEM-EDS point analysis for the pigments from which impurities have been removed. In the point analysis, as opposed to the mapping analysis, it was confirmed that the content of the 


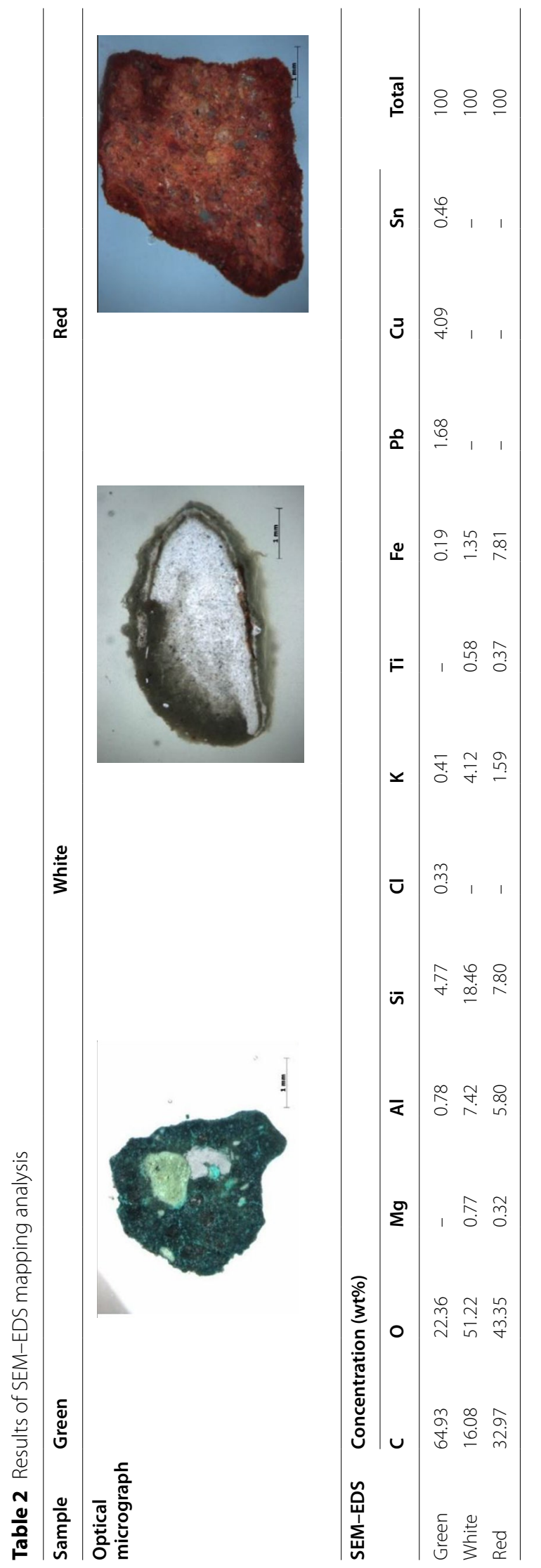




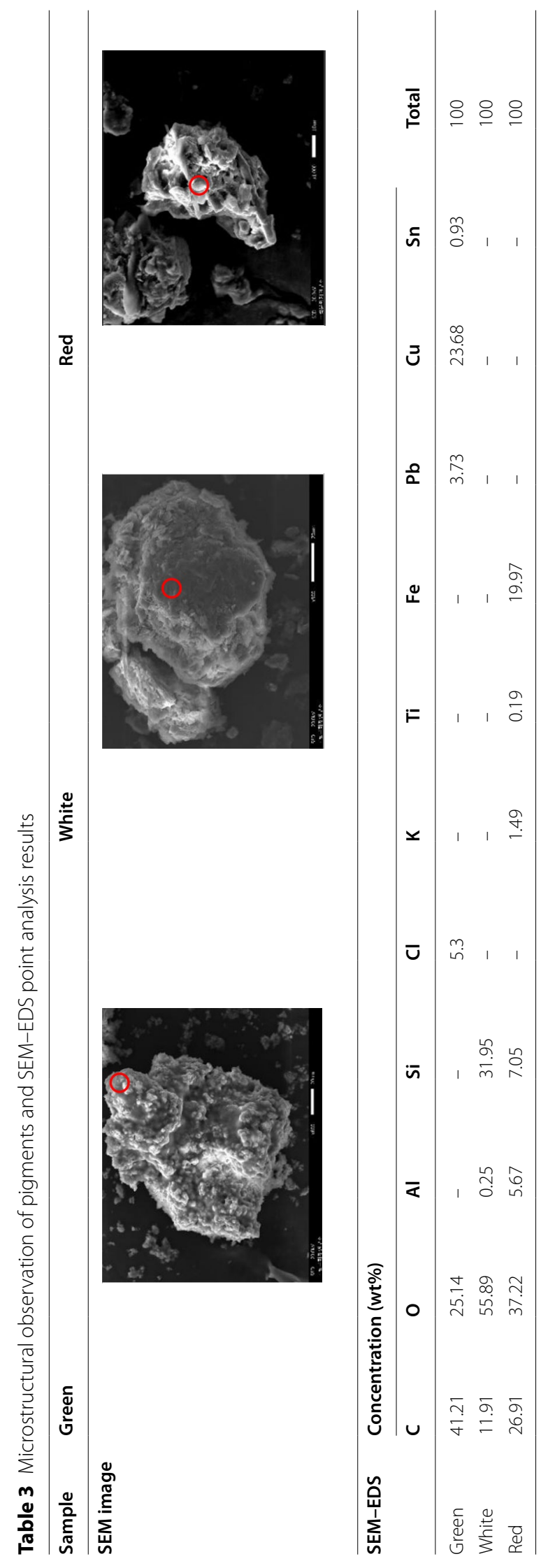


main elements increased. In the case of the green pigment, it was confirmed that the $\mathrm{Cu}(23.68 \%)$ and $\mathrm{Cl}(5.3 \%)$ content were increased compared to the SEM-EDS mapping analysis. In the white pigment, of $\mathrm{Si}$ (31.95\%), O, C, $\mathrm{Al}$ elements were quantified. The red pigment confirmed Fe (19.98\%), O, C, Si and Al elements.

\section{Principal element analysis}

An $x$-ray fluorescence spectrometer was used to conduct a quantitative analysis of the principal elements of the pigments. The results of the green pigment are as follows: $\mathrm{SiO}_{2} 31.20 \mathrm{wt} \%, \mathrm{CuO} 27.90 \mathrm{wt} \%, \mathrm{Al}_{2} \mathrm{O}_{3} 9.19 \mathrm{wt} \%$, and $\mathrm{PbO} 8.27 \mathrm{wt} \%$. The results of the white pigment are $\mathrm{SiO}_{2} 64.30 \mathrm{wt} \%$ and $\mathrm{Al}_{2} \mathrm{O}_{3} 18.20 \mathrm{wt} \%$. The results of the red pigment are as follows: $\mathrm{SiO}_{2} 40.60 \mathrm{wt} \%, \mathrm{Fe}_{2} \mathrm{O}_{3} 24.90$ $\mathrm{wt} \%$, and $\mathrm{Al}_{2} \mathrm{O}_{3} 19.80 \mathrm{wt} \%$ (Table 4).

\section{Particle size analysis}

In general, even with pigments having the same component and color, the smaller the granularity, the brighter the color. Size and color are interrelated, and in particular, saturation and brightness determined by the absorption and scattering characteristics are largely dependent on the size of the pigment according to the Mie theory [53]. This change in the properties of the material is a general feature of pigments, and the thicker the particles of the pigment, the more light is absorbed and the less it is reflected, thus causing the color to become darker. On the contrary, fine pigments become brighter. In addition, particle size can be used as an important parameter when determining pigments to be used for repair and restoration. In addition, it is reported that the size of pigment particles affects not only color but also important physical properties of pigments such as concealment, oil absorption, and workability $[43,54]$.

As in Fig. 10, the average particle size of the green pigment was the largest of the three types of pigment $(52.44 \mu \mathrm{m})$, followed by the red pigment $(35.88 \mu \mathrm{m})$ and the white pigment $(16.11 \mu \mathrm{m})$. As all three types of pigment have a distribution curve in the form of multiple peaks, it was judged that when preparing the pigments, they were neither purified to the same particle size nor separated according to particle size. The green pigment distribution ranges widely from 0.40 to $2000 \mu \mathrm{m}$. In addition, the span value of 9.02 shows that it has the widest degree of sorting range of the three types of pigment. The span value was used to represent the distribution width of particles. The narrower the distribution, the smaller the value. The span value of the white pigment is 5.0 and that of the red pigment is 4.8 , the lowest degree of sorting.

\section{Conclusion}

The raw material of the paper fragment was Brussonetia papyrifera, a source of bast fibers, which is estimated to date between CE 1455 to 1646 and is believed to have been made after the establishment of the Hoeamsa Temple site.

To identify the objective color value of the pigment, chromaticity measurements were performed, and the difference between the brightness value and redness levels of the three types of pigments was found to be remarkable. The color white had a high brightness value, whereas the red pigment exhibited a high degree of redness.

As a mineral characteristic of the three types of pigments, green pigments were identified as malachite and atacamite centered on the element $\mathrm{Cu}$, with cerussite also being detected; the elements $\mathrm{Cu}, \mathrm{Pb}$, and $\mathrm{Sn}$ were detected together in SEM-EDS. Accordingly, it is highly likely that pigments were made available mainly by combining malachite and atacamite, revealing the color green, with cerussite showing the color white. White pigments were white clay minerals-quartz, muscovite, and illite-whereas red pigments were composed of $\mathrm{Fe}, \mathrm{Al}$, and $\mathrm{Si}$ as main elements, and hematite and clay minerals such as illite and kaolinite as the other elements.

Through particle size analysis of pigments, it was feasible to infer the manufacturing process of pigments, and it is highly likely that the particle size distribution curve did not go through the glaze manufacturing process when pigments were being made. In the case of green-type pigments, it is judged that the particle size distribution curves are multiple since they are colored together with cerussite.

The key limitation of this study is the lack of samples collected. If sufficient samples are used, the degree of

Table 4 Concentration of elements in green pigment

\begin{tabular}{llll}
\hline & Green & White & Red \\
\hline $\mathrm{Al}_{2} \mathrm{O}_{3}$ & 9.19 & 18.20 & 19.80 \\
$\mathrm{CaO}$ & 0.20 & 0.07 & 0.17 \\
$\mathrm{CuO}$ & 27.90 & 0.05 & 0.56 \\
$\mathrm{Fe}_{2} \mathrm{O}_{3}$ & 2.19 & 3.03 & 24.90 \\
$\mathrm{~K}_{2} \mathrm{O}$ & 2.84 & 6.39 & 3.96 \\
$\mathrm{MgO}$ & 1.26 & 1.51 & 0.69 \\
$\mathrm{MnO}$ & 0.03 & 0 & 0.057 \\
$\mathrm{Na}{ }_{2} \mathrm{O}$ & 0.24 & 0.12 & 0.20 \\
$\mathrm{P}_{2} \mathrm{O}_{5}$ & 0.21 & 0.06 & 0.24 \\
$\mathrm{PbO}$ & 8.27 & 0.01 & 0 \\
$\mathrm{SiO}$ & 31.20 & 64.30 & 40.60 \\
$\mathrm{SnO}$ & 2.15 & 0 & 0 \\
$\mathrm{TiO}_{2}$ & 0.58 & 1.34 & 0.95 \\
$\mathrm{L.O.I}$ & 13.74 & 4.92 & 7.88 \\
$\mathrm{Total}$ & 100 & 100 & 100 \\
\hline
\end{tabular}




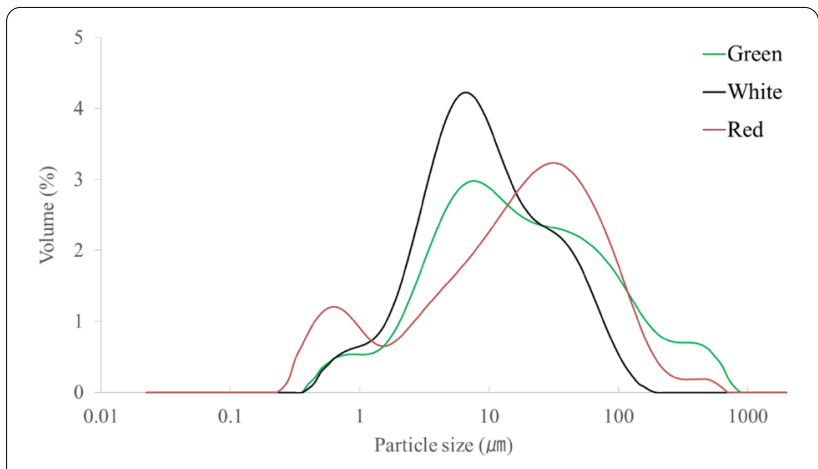

Fig. 10 Particle size distribution of pigments

\section{Declarations}

Competing interests

The authors declare that they have no competing interests.

\section{Author details}

${ }^{1}$ Institute of Cultural Heritage and History of Science \& Technology, University of Science and Technology Beijing, 30, Xueyuan Road, Haidian District, Beijing, People's Republic of China. ${ }^{2}$ Restoration Technology Division, National Research Institute of Cultural Heritage, Daejeon 34122, Republic of Korea. ${ }^{3}$ High Heritage Care, Daejeon 34013, Republic of Korea. ${ }^{4}$ Cultural Heritage Conservation Science Center, National Research Institute of Cultural Heritage, Daejeon 34122, Republic of Korea.

Received: 3 August 2021 Accepted: 19 January 2022

Published: 8 February 2022 aging and purification of fibers can be estimated through the double staining method (Saflanine + Astrablue).

Through this study, the ingredients of pigments, manufacturing processes, and methods of using pigments (regarding coloring) excavated from the Hoeamsa Temple site, one of the greatest temples that received a lot of reverence as a royal temple, were identified, and by measuring the date using paper fragments, it was possible to assess the characteristics of pigments and raw materials for paper fragments from the early to mid-Joseon period. It is anticipated that these findings can serve as basic data for cultural properties that use pigments such as paintings and dancheong cultural properties, and that they can also be utilized as scientific data if cultural properties need to be repaired or restored through traditional methods.

\section{Abbreviations \\ AMS: Accelerator mass spectrometer; SEM-EDS: Scanning electron micros- copy-energy dispersive spectroscopy; Arrow TM: Transparent membrane; Arrow D: Dislocation; Arrow C: Cross-marking; BP: Before present; Cer: Cerus- site; Qtz: Quartz; Mal: Malachite; Ata: Atacamite; Mus: Muscovite; Ilt: Illite; Hm: Hematite; Kao: Kaolinite.}

\section{Acknowledgements}

The authors would like to acknowledge the Korea Institute of Geoscience and Mineral Resources, which provided assistance in radiocarbon dating estimations. Special thanks to the officials of the Gyeonggi Cultural Heritage Research Institute, Gyeonggi Cultural Foundation for preserving precious cultural heritage samples.

\section{Authors' contributions}

$\mathrm{IH}$ designed and performed the experiments and interpreted the data. $\mathrm{IH}$ and HY wrote the manuscript. SW and JJ performed the X-Ray Diffraction and XRF. All authors read and approved the final manuscript.

\section{Funding}

This study was conducted as part of the National Research Institute of Cultural Heritage R\&D Project (Project number: NRICH-1605-C02F-1).

\section{Availability of data and materials}

Not applicable.

\section{References}

1. Lee SY. The changes in the construction method of full floor heating ondol facilities and its meaning in the early Joseon dynasty: revealed though the ondol remains of the Hoeam Temple site. J Korean Archaeol Soc. 2019:113(113):264-91.

2. Cho WC. Architecture archeology review and characteristics of structures of Buddhist stupa's building in Hoeamsa temple. J Local Hist Cult. 2016;19(2):111-40.

3. Kim SH. A study on development and utilization of content for Hoeamsa temple site. J Acad Assoc Glob Cult Contents. 2018;35:43-61.

4. Lee $\mathrm{HH}$. Research trend of the analysis and restoration study on traditional pigments. J Cult Herit Stud. 2015;48(1):132-47. https://doi.org/10. 22755/kjchs.2015.48.1.132.

5. Winter J. Identification of some early Korean pigments. Nat Museum J Art. 1989;43:9-36.

6. Berrie $\mathrm{BH}$. Rethinking the history of artists' pigments through chemical analysis. Ann Rev Anal Chem. 2012;5:441-59. https://doi.org/10.1146/ annurev-anchem-062011-143039.

7. Mun SW, Kang YS, Kim JS, Hwang GH, Park JH, Lee SM, Jeong HY. Analysis on characteristics of pigments manufactured with various Neorok produced from Mt. Gwangjeongsan. Pohang. J Conserv Sci. 2020;36(6):53340. https://doi.org/10.12654/JCS.2020.36.6.09.

8. Kim JS, Jeong HY, Byun DJ, Yoo MJ, Kim MN, Lee SM. Monitoring the change of physical properties of traditional dancheong pigments. J Conserv Sci. 2020;36(6):549-61. https://doi.org/10.12654/JCS.2020.36.6.11.

9. Yao LL. Multi-analytical approach to the study of pigments and binding media in precious ancient polychrome cultural relics [dissertation]. Zhejiang Univ. 2017. p. 5-10.

10. Song YN, Lee HH, Chung YJ, Lee HY. Comparison of painting characteristics on portraits by nondestructive analysis of Joseon dynasty in the 18th century-focusing on Yu Eon-ho's portrait. J Conserv Sci. 2016;32(1):89100. https://doi.org/10.12654/JCS.2016.32.1.09.

11. Nam JY, Han KO, Ji JE, Kim S, Lee HH, Kang DI, Han MS, Yang IS. Raman spectroscopy of the pigments on Korean traditional paintings. Vib Spectrosc. 2016;85:181-4. https://doi.org/10.1016/j.vibspec.2016.04.011.

12. Jung $\mathrm{CH}$. A study on pigment analysis of dancheong using hyperspectral technique: focusing on green colors [dissertation]. Korea Natl Univ Cult Herit. 2019. p. 106. http://www.riss4u.net/search/Search.do?isDetailSe arch $=$ Y\&searchGubun=true\&queryText $=$ znCreator,\%EC\%A0\%95\%EC\% B0\%B8\%ED\%9D\%AC\&colName=bib_t.

13. Song YN. Analysis of Korean dancheong pigment. [verbal presentation] 2021 inorganic heritage workshop of The Korea Society of Conservation Science for Cultural Heritage. 2021.

14. Hong TY, Choi KJ, Ha TW, Park BC, Sim Kl, Kim JH, Kim JH, Kwon JE, Lee S, Kang DI, Lee HH. Terahertz time-domain and Fourier-transform infrared spectroscopy of traditional Korean pigments. J Korean Phy Soc. 2014;64:727-31. https://doi.org/10.3938/jkps.64.727.

15. Jang SW, Park YS, Park DW, Kim JK. A study on dancheong pigments of old wooden building in Gwangju and Jeonnam. Korea Econ Environ Geol. 2010;43(3):269-78. 
16. Song IJ, Bang BS, Oh SM, Ha HY, Kwak YS. Dancheong colors used for Korean cultural heritage architecture restoration. Color Res Appl. 2018;43(4):586-95. https://doi.org/10.1002/col.22220.

17. National Research Institute of Cultural Heritage. Scientific investigation and analysis of traditional dancheong pigments. Chicago: Rem Design Press; 2020

18. National Research Institute of Cultural Heritage. Investigation of domestic sources of natural pigment raw materials. Cheshire: Graphic Press; 2017.

19. Standard specification for cultural property repair. https://www.cha.go.kr/ cop/bbs/selectBoardList.do?bbsld=BBSMSTR_1045\&mn=NS_03_09_01. Accessed 17 May 2021.

20. You MY. Archaeometric Interpretation, age dating and quantitative analysis of the roof tiles from Punggidong remain sites, Asan, Korea [dissertation]. Kongju Natl Univ. 2008. p. 40. http://www.riss4u.net/search/ detail/DetailView.do?p_mat_type $=$ be54d9b8bc7cdb09\&control_no= 8ead4f5b417f2253ffe0bdc3ef48d419\&keyword=\%ED\%92\%8D\%EA\%B8\% B0\%EB\%8F\%99.

21. Olsson IU. Radiocarbon dating history: early days, questions, and problems met. Radiocarbon. 2009;51(1):1-43. https://doi.org/10.1017/S0033 822200033695.

22. Ramsey CB. Development of the radiocarbon calibration program. Radiocarbon. 2013;55(2):720-30. https://doi.org/10.1017/S0033822200038212.

23. Collings T, Milner D. The identification of oriental paper-making fibres. Paper Conserv. 2010;3:51-79. https://doi.org/10.1080/03094227.1978. 9638509.

24. Yeon JA, Park WK. Wiggle matching radiocarbon dates of a Buddhist wooden tablet (Bulpae) at Songkwangsa temple, Suncheon, Korea. J Korea Furnit Soc. 2014;25(1):55-60.

25. Lee HS, Song HJ. The study on the radiocarbon dating of Cheongok-dong archaeological site, Ulsan. Conserv Studies. 2006;27:181-201.

26. Kim HS. A study on arrangement of a royal palace for Yangju archaeological site. J Munhwajae. 1991;24:368.

27. Choi YN. A study on hanji manufacturing in the Joseon dynasty. J EastWest Hist. 2003;9:31-65.

28. Yoo NJ. Topography, geological and geotechnical problems of Gangwondo. J Korea Geotechnical Soc. 2004;1:125-33.

29. Park JM. A research of characteristics of white porcelain manufacturing of Naesusa(內需司) during the first half of the Joseon dynasty with white porcelain inscription of 'Cheo(處). J Korean Field Archaeol. 2015;22:53-74. https://doi.org/10.35347/jkfa.2015.22.53.

30. Hunter D. Papermaking: the history and technique of an ancient craft. New York: Dover Publications; 2011. p. 48-63.

31. Park JK. The production of paper and "So(所) production system" of Goryeo dynasty (918-1392 AD). Korean Stud J. 2011;35:49-74.

32. Ilvessalo-Pfäffli MS. Fiber atlas: identification of papermaking fibers. Berlin: Springer; 1995

33. Shin YN. Paper characteristics of Chinese old book at the Jangseogak archives collection [dissertation]. Chungbuk Natl Univ. 2017; p.1-143. http://www.riss4u.net/search/detail/DetailView.do?p_mat_type=be54d 9b8bc7cdb09\&control_no=eaedb76dc89c5866ffe0bdc3ef48d419\& keyword=\%EC\%9E\%A5\%EC\%84\%9C\%EA\%B0\%81.

34. Lee HS, Kang KY, Kim DY, Jo BM. Physical properties of traditional handicraft paper in Korea, China and Japan. J Korean Wood Sci Technol. 2011; p. 382-383. http://kswst.or.kr/html/sub03_06.asp.

35. $\mathrm{Go} \mathrm{IH}$, Jo AH, Ye JH, Jeong $\mathrm{SH}$. Analysis of domestic research trends on Korean paper hanji. J Conserv Sci. 2017;33(6):457-66. https://doi.org/10. 12654/JCS.2017.33.6.05

36. Ahn JY, Bae SB. Investigation of paper characteristics on old documents related to the head family of admiral Yi Sun-sin. J Conserv Sci. 2018;34(5):407-20. https://doi.org/10.12654/JCS.2018.34.5.09.

37. Adamopoulos S, Oliver JV. Fiber composition of packaging grade papers as determined by the Graff " $\mathrm{C}$ "staining test. Wood Fiber Sci. 2006;38(4):567-75.

38. Isenberg $\mathrm{H}$. Pulp and paper microscopy. Wisconsin: The Institute of Paper Chem Appleton; 1967. p. 164.

39. Lee SH. Identification of plant fibers designated on archives as the materials of Korean traditional paper (hanji) [dissertation]. Chungbuk Natl Univ. 2006; p. 1-91.

40. Go IH, Jeong SH. Anatomical, morphological, and chemical characteristics of paper-mulberry wood and bast fiber for raw material of Korean paper (hanji). J Conserv Sci. 2018;35(6):517-24. https://doi.org/10.12654/JCS. 2018.34.6.07.

41. Elias M. Relationship between the size distribution of mineral pigments and color saturation. Appl Opt. 2011;50(16):2464-73. https://doi.org/10. 1364/AO.50.002464.

42. Gueli AM, Bonfiglio G, Pasquale S, Troja SO. Effect of particle size on pigments color. Color Res Appl. 2019;42(2):236-43. https://doi.org/10.1002/ col.22062.

43. Park JH, Jeong HY, Go IH, Jeong SL, Jo AH. A study on the physical properties of seokrok and noerok used as green pigment. J Conserv Sci. 2015;31(4):429-41. https://doi.org/10.12654/JCS.2015.31.4.10.

44. Han KS. Pigments of mural paintings in Dunhuang Mogao Caves. Korean Bulletin of Art History. 2001;232:177-99.

45. Han MS, Kim JH, Lee JJ. A scientific analysis of dancheong pigments at Yaksajeon hall in Gwallyoungsa temple. Munhwajae Korean J Cul Herit Stud. 2014;47(1):18-31. https://doi.org/10.22755/kjchs.2014.47.1.18.

46. National Research Institute of Cultural Heritage. Natural inorganic pigment. Digital OA Planning Press. 2020; p. 1-188. https://www.cha.go.kr/ cop/bbs/selectBoardArticle.do?nttld=79386\&bbsld=BBSMSTR_1021\& pagelndex $=7 \&$ pageUnit $=10 \&$ search $C n d=$ title\&searchWrd $=\&$ ctgry $\mathrm{Lrcls}=\& \mathrm{ctgryMdcls}=\& \mathrm{ctgryS} \mathrm{mcls}=\& n \mathrm{tcStartDt}=\& n \mathrm{ntcEndDt}=\&$ searc hUseYn $=Y \&$ searchYear $=\& m n=N S 4$

47. Lee JJ, Han MS, Kwon HN, Lee JS, Yun JH, Kwon YM. A comparative study on characteristics of fabrics and coloring pigments of Buddhist paintings of Geumtapsa Temple and Manyeonsa temple. J Buddh Art. 2019;28:523-46.

48. Lee EW, Gyeong YJ, Yun JH, Kwon YM, Won SJ, Seo MS, Lee JJ. Scientific study of characteristics and material properties of hanging painting of Eunhaesa temple. J Conserv Sci. 2019;35(6):689-700. https://doi.org/10. 12654/JCS.2019.35.6.12.

49. Oh JS, Lee SL, Hwang MY. Research on copper and chlorine-based (copper trihydroxychloride) green pigments. J Cult Herit Stud. 2020;53(2):64-87.

50. Kang YS, Mun SW, Lee SM, Jeong HY. A study on the characteristics of verdigris manufactured by acid corrosion method. J Conserv Sci. 2020;36(3):178-86. https://doi.org/10.12654/JCS.2020.36.3.03.

51. Eastaugh N, Walsh V, Chaplin T, Siddall R. The pigment compendium-a dictionary of historical pigments. Oxford: Routledge; 2004.

52. Yoo YM, Han MS, Lee JJ. Species and characteristics of particles for traditional red and green pigments used in temples. J Conserv Sci. 2014;30(4):365-72. https://doi.org/10.12654/JCS.2014.30.4.05

53. Mie G. Beiträge zur Optik trüber Medien, speziell kolloidaler Metallösungen. Ann der Physik. 1908;330(3):377-445. https://doi.org/10.1002/andp. 19083300302.

54. Go IH, Jeong HY, Park JH, Jeong SL, Jo AH. The characteristics of particle size in natural mineral pigment for azurite raw material. J Conserv Sci. 2015;31(4):331-9. https://doi.org/10.12654/JCS.2015.31.4.01.

\section{Publisher's Note}

Springer Nature remains neutral with regard to jurisdictional claims in published maps and institutional affiliations.

\section{Submit your manuscript to a SpringerOpen ${ }^{\circ}$ journal and benefit from:}

- Convenient online submission

- Rigorous peer review

- Open access: articles freely available online

- High visibility within the field

Retaining the copyright to your article

Submit your next manuscript at springeropen.com 